\title{
A Perspective on Polylactic Acid-Based Polymers Use for Nanoparticles Synthesis and Applications
}

\author{
Tommaso Casalini ${ }^{1 *}$, Filippo Rossi ${ }^{2}$, Andrea Castrovinci ${ }^{1}$ and Giuseppe Perale ${ }^{1,3}$ \\ ${ }^{1}$ Polymer Engineering Laboratory, Department of Innovative Technologies, Institute for Mechanical Engineering and Materials \\ Technology, University of Applied Sciences of Southern Switzerland, Manno, Switzerland, ${ }^{2}$ Department of Chemistry, \\ Materials and Chemical Engineering "Giulio Natta", Politecnico di Milano, Milan, Italy, ${ }^{3}$ Ludwig Boltzmann Institute for \\ Experimental and Clinical Traumatology, Vienna, Austria
}

\section{OPEN ACCESS}

Edited by:

Anderson Oliveira Lobo,

Federal University of Piauí, Brazil

Reviewed by:

Jianxun Ding,

Changchun Institute of Applied

Chemistry (CAS), China

Edson Cavalcanti Silva-Filho,

Federal University of Piauí, Brazil

*Correspondence:

Tommaso Casalin

tommaso.casalini@supsi.ch

Specialty section:

This article was submitted to

Biomaterials,

a section of the journal

Frontiers in Bioengineering and

Biotechnology

Received: 05 July 2019

Accepted: 26 September 2019

Published: 11 October 2019

Citation:

Casalini T, Rossi F, Castrovinci A and

Perale G (2019) A Perspective on

Polylactic Acid-Based Polymers Use

for Nanoparticles Synthesis

and Applications.

Front. Bioeng. Biotechnol. 7:259.

doi: 10.3389/fbioe.2019.00259
Polylactic acid (PLA) - based polymers are ubiquitous in the biomedical field thanks to their combination of attractive peculiarities: biocompatibility (degradation products do not elicit critical responses and are easily metabolized by the body), hydrolytic degradation in situ, tailorable properties, and well-established processing technologies. This led to the development of several applications, such as bone fixation screws, bioresorbable suture threads, and stent coating, just to name a few. Nanomedicine could not be unconcerned by PLA-based materials as well, where their use for the synthesis of nanocarriers for the targeted delivery of hydrophobic drugs emerged as a new promising application. The purpose of the here presented review is two-fold: on one side, it aims at providing a broad overview of PLA-based materials and their properties, which allow them gaining a leading role in the biomedical field; on the other side, it offers a specific focus on their recent use in nanomedicine, highlighting opportunities and perspectives.

Keywords: polylactic acid, degradation, processing, nanomedicine, nanoparticles

\section{INTRODUCTION}

Polylactic acid (PLA), classified as an aliphatic polyester because of the ester bonds that connect the monomer units, has gained a key role in the biomedical field for a wide range of applications: suture threads, bone fixation screws, devices for drug delivery, just to scratch the surface. PLA merges several interesting properties that make it an ideal candidate for biomedical applications.

PLA naturally degrades in situ through hydrolysis mechanism: water molecules break the ester bonds that constitute polymer backbone. This eliminates the necessity of additional surgeries in order to remove the device, improving patient recovery and optimizing health system costs.

The main phenomena involved in the degradation mechanisms and the most important factors that influence hydrolysis rate are currently well-established in scientific literature, thanks to a devoted research activity that reached the peak between the 1980s and the 1990s. Consequently, degradation kinetics and mechanical properties can be tailored by properly tuning few polymer properties (such as composition or molecular weight), thus leading to the development of biomedical devices optimized for each specific application. Degradation products (composed of lactic acid and its short oligomers) are recognized and metabolized by the body itself: this gives PLA an intrinsic biocompatibility that dampens the attainment of critical immune responses. 
In addition, PLA can be processed with standard and established technologies, such as injection molding, extrusion, etc.

After this brief summary, whose main points will be discussed in the following sections, it should be no more surprising why PLA attracted a lot of attention and enthusiasm in the biomedical field. These features make PLA a suitable option also for the new paradigm recently introduced by nanomedicine, where nanomaterials (whose size is similar to molecules of biological interest, such as proteins or viruses) are distributed within the human body and can be internalized by cells.

Nanomedicine offers new unprecedented chances, thanks to the synthesis of nanoparticles, which can be employed for the targeted delivery of drugs, vaccines and genes. On the other hand, nanomaterials can also give rise to new side effects due to specific interactions with the biological components (proteins, carbohydrates, lipids) present in body fluids (blood, plasma, interstitial fluids).

The first part of this review guides the interested reader through the main peculiarities of PLA, underlining the reasons why it emerged as a material of choice in the biomedical field. The second part of the manuscript is focused on the use of PLA for the synthesis and application of nanoparticles, from the synthetic routes of nanovectors to perspectives and opportunities.

\section{POLYLACTIC ACID-BASED MATERIALS: GENERAL DESCRIPTION AND SYNTHESIS ROUTES}

Polylactic acid is a hydrophobic polymer that belongs to the class of biomaterials commonly referred as poly- $\alpha$-hydroxy acids, poly- $\alpha$-esters or aliphatic polyesters. It is synthesized starting from lactic acid (LA; 2-hydroxypropanoic acid), which a watersoluble monomer that exhibits two enantiomeric forms, namely L-(+)-LA and D-(-)-LA, as shown in Figure 1.

Although both enantiomers are employed in industrial practice, $\mathrm{L}-(+)-\mathrm{LA}$ is the isomer of interest for biomedical applications since it is involved in the cellular metabolism of the human body and reduces the risk of adverse reactions. In in vivo environment L-(+)-LA can be either incorporated into the Krebs' cycle or converted into glycogen in the liver; eventually it is eliminated as water and carbon dioxide from the lungs (Sheikh et al., 2015). PLA can be produced starting from pure L-lactic and D-lactic isomers, which leads to poly-L-lactic (PLLA) acid and poly-D-lactic acid (PDLA) homopolymers, respectively; if a racemic mixture of $\mathrm{L}$ - and $\mathrm{D}$-monomers is employed, poly- $\mathrm{D}, \mathrm{L}-$ lactic acid (PDLLA) copolymer is obtained. The stereochemistry has a relevant impact on material properties: PLLA is a semicrystalline polymer, while PDLLA is an amorphous polymer with no melting point. In addition, degradation rate of PLLA is significantly slower than PDLLA, because of the presence of crystalline regions. Main advantages and disadvantages of PLA use and production are summarized in Table $\mathbf{1}$.

Focusing on lactic acid itself, synthesis can be performed in different ways; the most popular route is the following one (Storti and Lattuada, 2017):

$$
\begin{aligned}
\mathrm{CH}_{3} \mathrm{CHO}+\mathrm{HCN} \rightarrow & \mathrm{CH}_{3} \mathrm{CH}(\mathrm{OH}) \mathrm{CN} \\
\mathrm{CH}_{3} \mathrm{CH}(\mathrm{OH}) \mathrm{CN}+2 \mathrm{H}_{2} \mathrm{O}+\mathrm{HCl} \rightarrow & \mathrm{CH}_{3} \mathrm{CH}(\mathrm{OH}) \mathrm{COOH} \\
& +\mathrm{NH}_{4} \mathrm{Cl} \\
\mathrm{CH}_{3} \mathrm{CH}(\mathrm{OH}) \mathrm{COOH}+\mathrm{CH}_{3} \mathrm{OH} \leftrightarrow & \mathrm{CH}_{3} \mathrm{CH}(\mathrm{OH}) \mathrm{COOCH}_{3} \\
& +\mathrm{H}_{2} \mathrm{O}
\end{aligned}
$$

Lactonitrile, obtained from acetaldehyde and hydrogen cyanide (1), is hydrolysed at low $\mathrm{pH}$ in order to lactic acid (2); it is subsequently converted to methyl lactate (3) through esterification and eventually recovered and purified by distillation. Lactic acid and methanol are obtained through hydrolysis from lactate; methanol is recycled in step (3). Anyway, this kinetic pathway leads to a racemic mixture.

Bacterial fermentation of sugar solutions is currently the most employed process; this process leads to high yields and, depending on the chosen type of bacteria, it allows obtaining one given stereoisomer or the racemic mixture. It is estimated that about $90 \%$ of the total LA produced worldwide is currently obtained with this procedure.

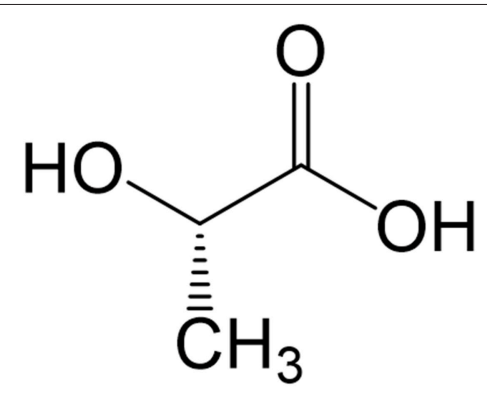

L-(+)-Lactic acid

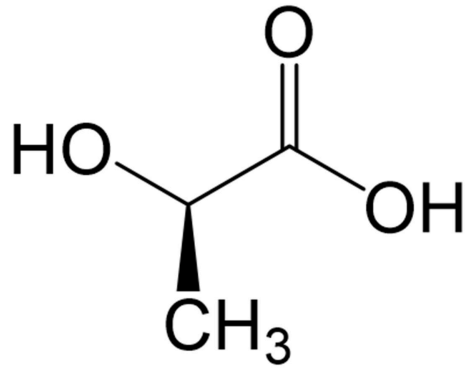

D-(-)-Lactic acid

FIGURE 1 | Enantiomeric forms of lactic acid. 
TABLE 1 | Main advantages and disadvantages of PLA.

Advantages
Eco-friendliness: PLA is produced
from renewable sources (corn, wheat,
rice). In addition, it is biodegradable,
recyclable and compostable. Its
production consumes $\mathrm{CO}_{2}$.

Biocompatibility: main PLA degradation product, lactic acid, is non-toxic and metabolized by the organism itself.

Processability: PLA has a better thermal processability than other biopolymers. It can be processed through injection molding, film extrusion, blow molding, thermoforming, fiber spinning, and film forming.

Energy saving: PLA requires 25-55\% less energy than petroleum-based polymers.

\section{Disadvantages}

Poor thoughness: PLA is a very brittle material, whose elongation at break is $<10 \%$. This can represent a limit for those applications that need plastic deformation at high stress levels.

Slow degradation rate: PLA naturally degrades through hydrolysis, whose rate depends on may factors, such as crystallinity and molecular weight. Slow PLA degradation leads to high life time of devices in vivo, and can raise issues for the disposal of commodities.

Hydrophobicity: PLA is a relatively hydrophobic material (static water contact angle value is about $80^{\circ}$ ). This results in low cell affinity and can lead to inflammatory response upon direct contact to biological fluids.

Lack of reactive side chain groups: PLA is chemically inert, which makes surface functionalization and bulk modification challenging tasks.

Adapted from Farah et al. (2016).

In this framework, the critical step is the subsequent LA purification, which is expensive and determines process profitability. Commonly used techniques are liquid extraction, membrane separation, ion exchange, electrodialysis, and reactive distillation.

Polymer synthesis can be carried out through step growth polymerization or ring opening polymerization. Step growth polymerization simply takes advantage of the reactivity of the two LA functional groups: indeed, the polycondensation of hydroxyl and carboxyl moieties leads to the formation of the ester bonds that constitute polymer backbone. This synthetic route has several drawbacks: long residence times are required for longer chains (leading to unwanted side reactions, like transesterification), challenging reaction conditions (temperatures up to $250^{\circ} \mathrm{C}$ and vacuum up to 100 mbar) and continuous water (side product of polycondensation) removal. Chain extenders (e.g., isocyanates or epoxides) can be in principle employed, although this approach has an inevitable impact on material purity and quality.

At industrial scale ROP is the most popular process because of its advantages: mild process conditions, short residence times, absence of side products and high molecular weights. The most widely used catalyst is 2-ethylhexanoic tin(II) salt (also referred as stannous octoate $\left.\left[\mathrm{Sn}(\mathrm{Oct})_{2}\right]\right)$, approved by United Stated Food and Drug Administration (FDA) and usually employed along with an alcohol as cocatalyst. The real bottleneck of ROP is the availability of cyclic monomers as well as their optical and chemical purity, since impurities have detrimental effects on material properties due to the sensitivity of the reaction to residual non-cyclic monomers. The cyclic raw material for PLA is constituted by cyclic dimer lactide, which exhibits three stereoisomeric forms, as shown in Figure 2: LL-, DD-, and D,L(also referred a meso-lactide).

Lactide is usually produced through backbiting kinetic mechanism is then (promoted with suitable process conditions) starting from low molecular weight prepolymer; cycles are eventually collected by distillation. Other synthesis routes are azeotropic dehydration and enzymatic polymerization. PLAbased polymers synthesis routes are summarized in Figure 3.

PLA is widely employed in the biomedical field because of its biocompatibility and its processability, since it can be processed with a wide range of techniques, such as extrusion, injection molding, injection stretch blow molding, film and sheet casting, extrusion blow film, thermoforming, foaming, fiber spinning, electro spinning, blending, compounding, and nanocompositing.

\section{PHYSICAL AND CHEMICAL PROPERTIES}

PLA can be seen as a "family" of polymers, which include homopolymers PLLA and PDLA (synthesized from mixtures of pure L- or D-lactic acid) and the copolymer PDLLA (obtained from the racemic mixture). This has a remarkable impact on material properties because of the involved stereochemistry: PLLA and PDLA are semicrystalline polymers, while PDLLA is usually amorphous. The final crystallinity depends also on the thermal and mechanical history, mainly due to fabrication processes. Mechanical properties are summarized in Table 2; values are expressed as ranges, since they strongly depend on the characteristic of the tested material (molecular weight, crystallinity, processing, etc.) as well as testing procedure (Van De Velde and Kiekens, 2002).

Polymer crystallinity influences mechanical and physical properties such as hardness, modulus, tensile strength, stiffness, and melting points. If the amount of PLLA is higher than $90 \%$ the polymer is semicrystalline, while lower amounts (and thus a lower optical purity) lad to an amorphous polymer. The density values lie in small range depending on the composition, as shown in Table 2.

PLA is soluble in dioxane, acetonitrile, chloroform, methylene chloride, 1,1,2-trichloroethane and dichloroacetic acid, while it is only partially soluble in ethyl benzene, toluene, acetone and tetrahydrofuran, only when heated to boiling temperature. PLA is not soluble in water, alcohols, and linear hydrocarbons. Crystalline PLLA cannot be dissolved in acetone, ethyl acetate, or tetrahydrofuran.

It is worth mentioning that polymer properties can change after processing, because of thermal and mechanical stresses. PLA undergoes thermal degradation above $200^{\circ} \mathrm{C}$, although degradation rate and extent depend on variables like time, temperature, low molecular weight impurities, and catalyst amount (Carrasco et al., 2010).

The success of PLA passes also through its versatility, since material properties can be modified in several ways. They can 
<smiles>C[C@@H]1OC(=O)[C@@H](C)OC1=O</smiles>

L-lactide<smiles>C[C@@H]1OC(=O)[C@@H](C)OC1=O</smiles>

meso-lactide<smiles>C[C@@H]1OC(=O)[C@@H](C)OC1=O</smiles>

D-lactide

FIGURE 2 | Cyclic dimers for ROP process.

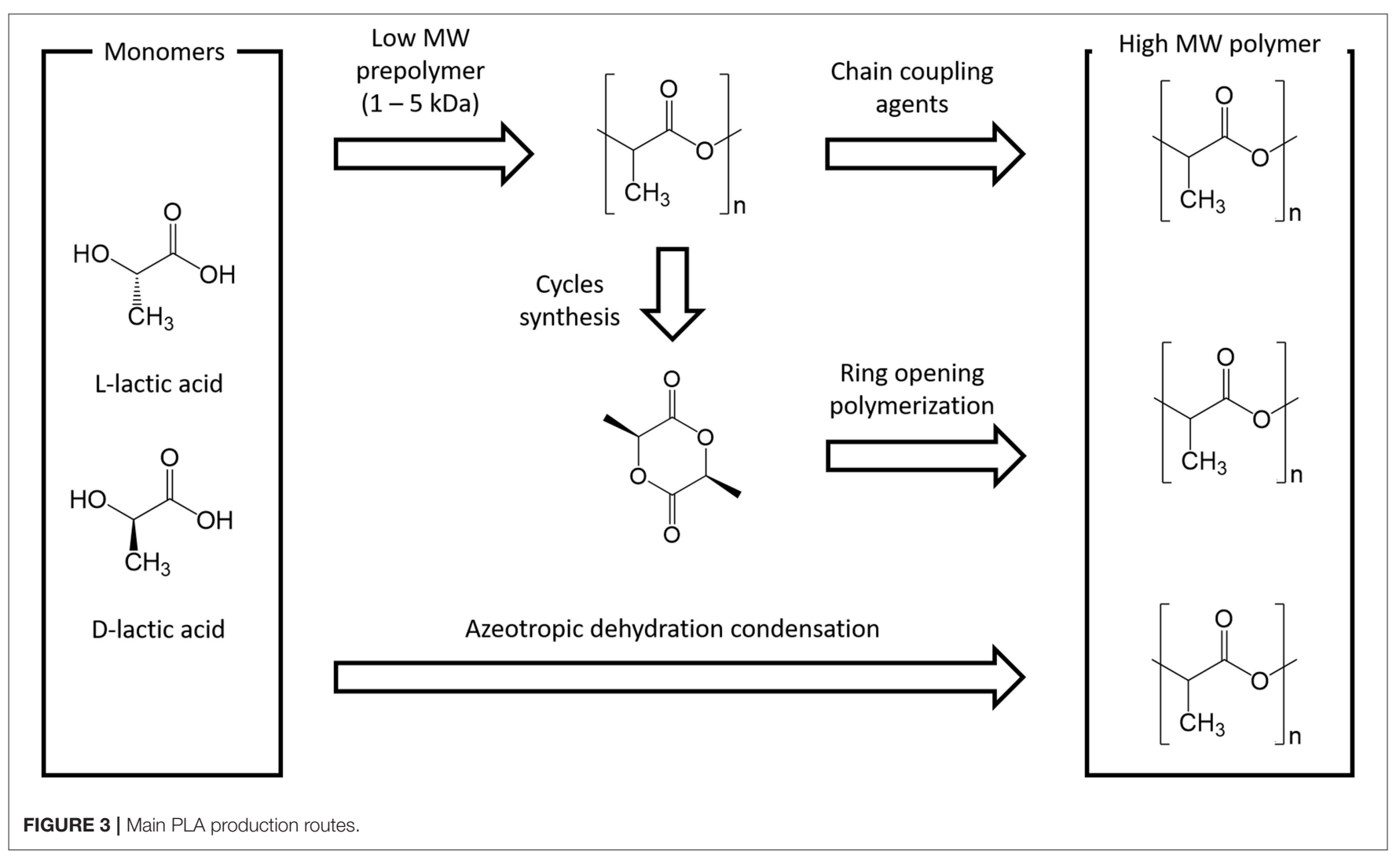

be tuned, e.g., through the addition of suitable plasticizers, widely used in order to improve processability and flexibility of polymers. Focusing on semicrystalline PLA, plasticizer addition decreases $T_{g}$, as well as $T_{m}$ and crystallinity.

PLA can be blended with biodegradable or non-biodegradable polymers (such as polyethylene, polypropylene, chitosan, polystyrene, polyethylene terephthalate, and polycarbonates) (Saini et al., 2016) or by making composite materials (Murariu and Dubois, 2016) through the addition of carbon nanotubes, ceramic nanoparticles, natural fibers, and cellulose (Hamad et al.,
2018). A relevant example is constituted by PLA/hydroxyapatite (HA) composites for devices for bone healing, where HA micro or nanoparticles are dispersed into the polymer matrix (Rodenas-Rochina et al., 2015).

Another is the formation of stereocomplexes (Tsuji, 2016), which can be obtained by blending PLLA with PDLA (that is, the homopolymer composed by D-lactide units only) or adopting PLLA/PDLA block copolymers. The strong interactions between PDLA and PLLA blocks that derive from the formation of stereocomplex crystallization improves mechanical properties 
TABLE 2 | Mechanical properties of PLA-based polymers.

\begin{tabular}{lccc}
\hline Property & PLA & PLLA & PDLLA \\
\hline$\rho\left[\mathrm{g} \mathrm{cm}^{-3}\right]$ & $1.21-1.25$ & $1.24-1.30$ & $1.25-1.27$ \\
$\sigma[\mathrm{MPa}]$ & $21-60$ & $15.5-150$ & $27.6-50$ \\
$\mathrm{E}[\mathrm{GPa}]$ & $0.35-0.5$ & $2.7-4.14$ & $1-3.45$ \\
$\varepsilon[\%]$ & $2.5-6$ & $3.0-10.0$ & $2.0-10.0$ \\
$\mathrm{~T}_{\mathrm{g}}\left[{ }^{\circ} \mathrm{C}\right]$ & $45-60$ & $55-65$ & $50-60$ \\
$\mathrm{~T}_{\mathrm{m}}\left[{ }^{\circ} \mathrm{C}\right]$ & $150-162$ & $170-200$ & amorphous-no melt point \\
\hline
\end{tabular}

$\rho$, density; $\sigma$, tensile strength; $E$, elastic modulus; $\varepsilon$, ultimate strain; $T_{g}$, glass transition temperature; $T_{m}$, melting temperature. Taken from Farah et al. (2016).

and thermal stability, slows down degradation rate and increase PLA barrier properties, allowing a more prolonged drug release. PLA-based stereocomplexed materials, by virtue of their improved stability, attracted a lot of interest also for biomedical applications, such as fibers and nanoparticles for drug delivery applications (Jing et al., 2016).

PLA-based materials can be also assembled in complex molecular architectures (Corneillie and Smet, 2015), leading to branched polymer chains, star-shaped structures (Michalski et al., 2019), grafted chains (Nagahama et al., 2007), and crosslinked matrices (Tsuji, 2016). If synthesized with both PLLA and PDLA blocks, stereocomplexation can be achieved also with these complex structures (Nagahama et al., 2007; Fan et al., 2013; Sveinbjornsson et al., 2014), which found as well-potential applications in the biomedical field for the synthesis of hydrogels, nanoparticles and micelles for drug delivery purposes.

Another popular way to tune material properties is the copolymerization with glycolic acid, which leads to the well-known polylactic-co-glycolic random copolymer (PLGA). Copolymerization is also performed with caprolactone, which allows obtaining polylactic-co-caprolactone (PLCL). Another strategy to improve material hydrophilicity is the synthesis of PLA and polyethylene glycol (PEG) block copolymers.

PLA (as well as its copolymers) degrades because of hydrolysis mechanism: water breaks the ester bonds that constitute polymer backbone, according to the following mechanism:

$$
P_{n+m}+H_{2} \mathrm{O}+H^{+} \leftrightarrow P_{n}+P_{m}+H^{+}
$$

where $P_{n+m}, P_{n}$, and $P_{m}$ are polymer chains composed by $n+m, n$, and $m$ monomer units, respectively, $\mathrm{H}_{2} \mathrm{O}$ is a water molecule and $\mathrm{H}^{+}$indicates that hydrolysis is catalyzed in acidic environment. The most important phenomena that govern PLA degradation are currently rationalized and accepted in scientific literature (Casalini, 2017). Two degradation regime can be distinguished. If hydrolysis rate is higher than diffusion rate, surface, or heterogeneous degradation takes place; only polymer surface experiences degradation and erosion (i.e., mass loss), while the bulk remains intact. The shape of the device remains unchanged, but its volume decreases in time. On the other hand, if water penetration is much faster than water consumption, homogeneous, or bulk degradation occurs: degradation rate is essentially equal in every point of the matrix and the volume does not appreciably change in time. Mass loss is observed after a certain time interval, when chain scission has created oligomers that are mobile enough to diffuse through the matrix toward the environment. Another relevant aspect is autocatalysis: polymer degradation creates small fragment that lower $\mathrm{pH}$-value by virtue of their dissociated carboxyl terminal group, thus enhancing hydrolysis rate. In other words, $\mathrm{pH}$ decreases as degradation continues and this results in an autocatalytic behavior. Notably, when mass transport resistances and/or mean diffusive paths are relevant, a transition from homogeneous to heterogeneous degradation may occur. In this case, oligomers accumulate in the core of the device, locally lowering the $\mathrm{pH}$; consequently, degradation is faster in the bulk than close to the surface. In order to discriminate the degradation mechanism, Von Burkersroda et al. (2002) proposed a distinctive parameter called critical thickness $L_{\text {crit }}$; if the characteristic size of the device (e.g., the radius of a sphere) is larger than the critical thickness surface degradation occurs, otherwise bulk degradation govern matrix hydrolysis mechanism.

A scheme is provided in Figure 4.

The discussed mechanisms represent asymptotic cases and the observed experimental behavior is usually one of the many shades of gray in between.

$L_{\text {crit }}$ depends on the interplay between degradation and diffusion kinetics, and at a first glance, it depends on the specific material. Von Burkersroda et al. (2002) computed the values of $L_{\text {crit }}$ for some polymers of interest; the reference value for aliphatic polyesters is $7.4 \mathrm{~cm}$. The main phenomena behind PLA degradation can be summarized as follows (Casalini, 2017):

- Water penetrates into the polymer matrix from the surrounding environment through diffusion. PLA is hydrophobic and polymer dissolution is absent; volumetric swelling is negligible;

- While water diffuses, it breaks the ester bonds and causes chain scission;

- The resulting small oligomers diffuse out of the matrix; if their concentration in the core is high because of mass transport resistances, degradation is locally faster due to autocatalysis;

- Diffusivities of each compound increase as molecular weight decreases, since chain scission creates new and wider diffusive paths;

- In in vivo environment, an additional contribution to degradation is given by enzymes, which contribute to the erosion of device surface (vide infra).

Degradation rate depends on several factors, such as (Alexis, 2005):

- Polymer composition: Generally speaking, degradation increases as material hydrophilicity increases. PLLA degradation is slower than PDLLA because of the presence of crystalline regions.

- $p H$ : As mentioned, hydrolysis of ester bond is favored at low $\mathrm{pH}$-values, although there are some experimental evidences that basic conditions can speed up chain scission.

- Device geometry: Device size can discriminate the attainment of bulk or surface degradation (vide supra). 


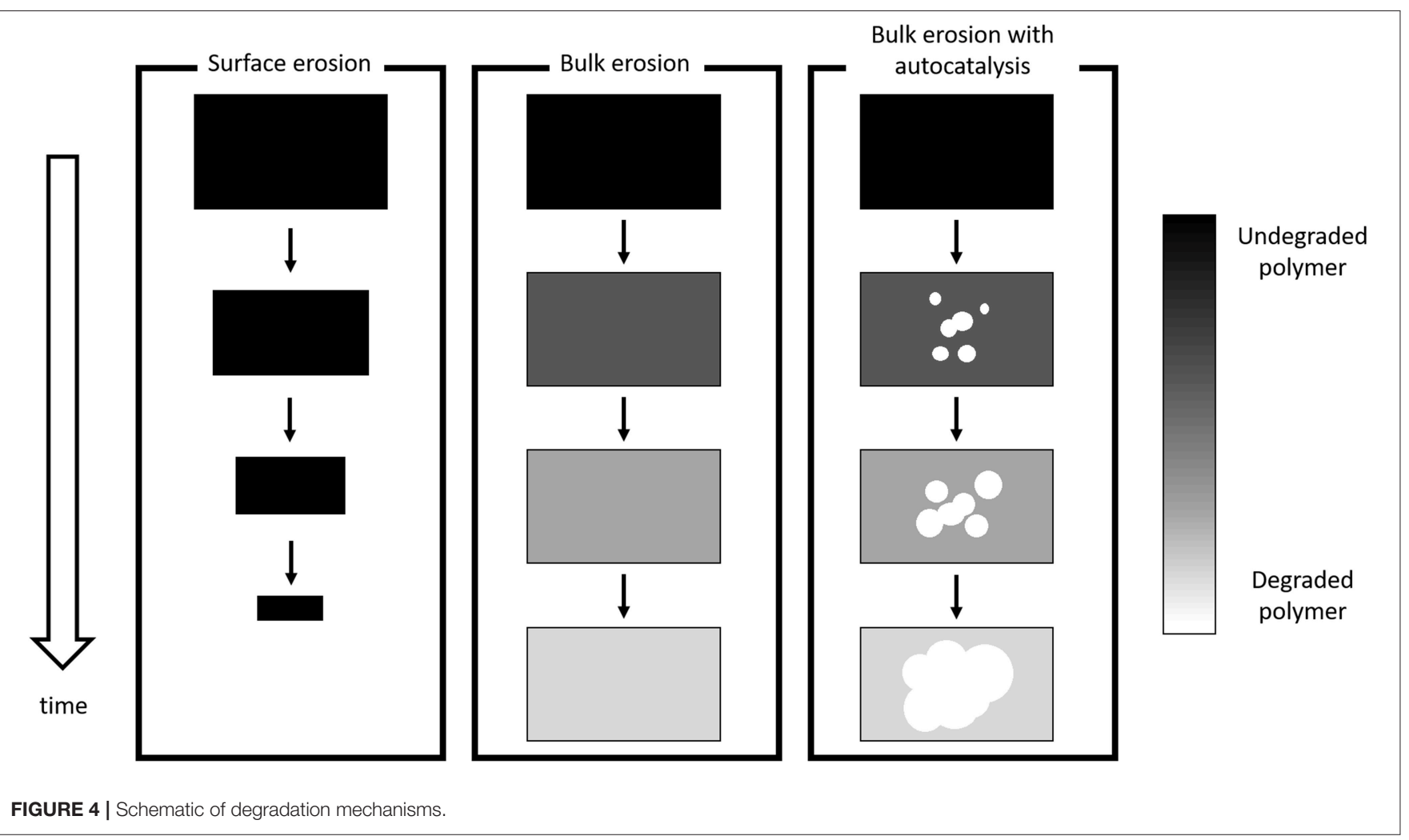

- Molecular weight: Degradation rate decreases as molecular weight increases, because of the lower water uptake. In addition, high molecular weight values imply a lower concentration of carboxyl end groups.

- Crystallinity: Broadly, semicrystalline polymers are characterized by a slower degradation rate than amorphous ones, since crystallites regions are less subjected to hydrolysis. However, there are still some inconsistent results, which may depend on the different process methodologies. It has also been observed that the short chains that derive from the degradation of amorphous regions gain enough mobility to organize themselves in crystalline regions.

- Addition of drugs and/or additives: The addition of acidic compounds can enhance hydrolysis rate, while basic compounds can neutralize carboxyl end groups and enhance degradation through base catalysis. The addition of plasticizers can promote water diffusion and water uptake, enhancing degradation rate.

- Sterilization: The use of beta or gamma irradiation or sterilization results in undesired reactions such as chain scissions and cyclization, that lower molecular weight and enhance degradation rate.

- Mechanical stress: Stress fields due to specific applications (e.g., fixation screw) enhance degradation rate.

- Fabrication processing: Thermal and mechanical stresses experienced by the polymer during commonly employed processing techniques (extrusion, injection molding, etc.) can lead to decrease in molecular weight and increase of degradation rate.
By virtue of a critical thickness equal to $7.4 \mathrm{~cm}$, PLA-based devices usually experience homogeneous degradation, which can become heterogeneous when oligomer accumulation in the bulk occurs.

In in vivo environment, there is an additional contribution to degradation due to enzymes that cleave ester bonds, such as lipases, cutinases, serine proteases, PHB depolymerase, PCL depolymerase, elastase esterase, proteinase $\mathrm{K}$, and trypsin. This enzymatic degradation is a heterogeneous process since involves only device surface: enzymes are not able to diffuse in the polymer matrix and contribute to surface erosion through ester bonds cleavage (Armentano et al., 2018).

PLA-based materials are also subjected to thermal degradation; while this is not relevant for biomedical applications themselves (at body temperature, thermal degradation is absent), this should be taken into account in the fabrication process. Indeed, for temperature values above $200^{\circ} \mathrm{C}$ (Garlotta, 2001), PLA experiences not only hydrolysis but also lactide reformation, oxidative chain scission, intra- or intermolecular transesterification reactions.

\section{PROCESSES FOR NANOPARTICLES SYNTHESIS}

PLA-based materials experienced a wide success in biomedical field for several reasons: biocompatibility, low toxicity, degradation through hydrolysis and tailored physical and chemical properties through the selection of molecular weight or 
TABLE 3 | Overview of PLA biomedical applications.

\begin{tabular}{ll}
\hline Field & Application \\
\hline Orthopedic & $\begin{array}{l}\text { Peripheral nerve and spinal cord injury regeneration } \\
\text { Bioadsorbable screws } \\
\text { Meniscus repair } \\
\text { Guided bone regeneration }\end{array}$ \\
& Chest wall reconstruction \\
Cardiac & Stent \\
& Guided tissue regeneration \\
Dentistry & Biocompatible space fillers \\
& Suture \\
Plastic surgery & Reconstructive surgery \\
& Dermal fillers \\
Skin draft \\
General surgery & Hemia mesh \\
Ranecology & Stress incontinence mesh \\
Oncology & Theranostic imaging \\
& Nanoparticles for drug delivery
\end{tabular}

Adapted from Tyler et al. (2016).

through copolymerization, blending, or building more complex molecular architectures and processability. A proper tuning of polymer properties allows assuring the desired performances (in terms, e.g., of tensile strength or release rate) over a suitable time span, before an appreciable onset of degradation reactions. The natural degradation of PLA-based devices due to hydrolysis avoids the need of additional surgery for device removal, improving patient care.

All these advantages led to a wide range of applications, summarized in Table 3 for the sake of completeness.

Nanomedicine is an emerging field, focused on the development and application of engineered nanomaterials, whose size (from 1 to $1,000 \mathrm{~nm}$ according to the FDA draft guideline form 2017) is comparable to many molecules of biological interest, such as proteins and viruses. Devices like polymer nanoparticles, by virtue of their small size, can be internalized by cells and this opens a wide range of new opportunities for the development, e.g., of new carriers for the targeted delivery of drugs and vaccines or image contrast agents for diagnostic purposes. Because of the interesting properties of PLA-based polymers, it is not surprising that they experienced and are still experiencing a great interest as starting materials for the synthesis of nanoparticles.

The most frequently used and promising methods to formulate nanosized particles can be divided in four categories according to the fundamental physical principles, as summarized by Lee et al. (2016). The main challenges are the control of particle size and an efficient drug encapsulation.

\section{Emulsion-Based Methods}

The single-emulsion/solvent-extraction method is the simplest approach for the synthesis of micro- and nanoparticles, including drug-loaded carriers. The polymer and, if needed, the hydrophobic drug are dissolved in a water-immiscible organic solvent and an emulsion in water phase is subsequently realized by adding a stabilizer and stirring. For the sake of completeness, oil in water $(\mathrm{o} / \mathrm{w})$ as well as oil in oil (o/o) and water in oil (w/o) emulsions can be suitable for this process.

The removal of the organic phase is carried out through evaporation at low pressure or vacuum or by solvent extraction; polymer particles are recovered by centrifugation or filtration and washed with water or buffer solutions in order to remove possible traces of solvent, stabilizer and free drug before lyophilization.

Single-emulsion approach leads to a poor encapsulation efficiency of hydrophilic drugs (such as peptides), which are mainly dispersed in the aqueous phase rather than the organic one. Double-emulsions methods aim at overcoming this issue. A water solution containing the hydrophilic active molecule is added to an organic solvent where the polymer is dissolved under stirring, in order to form a w/o (or an o/w) emulsion that is subsequently added to a second water phase containing a stabilizer. This leads to the formation of a w/o/w (or an $\mathrm{o} / \mathrm{w} / \mathrm{o}$ ) emulsion. The organic solvent is removed by means of evaporation under low pressure or vacuum and the resulting particles are washed (to safely remove traces of solvent, stabilizer, and free drug) before lyophilization.

Emulsion-based methods, despite their simplicity, need the optimization of several process parameters, such as phase volumes (oil and water), polymer, drug and stabilizer concentration, type of solvents, and stirring rate.

Examples of particles produced with emulsion-based methods are provided in Table 4.

\section{Precipitation-Based Methods}

Nanoprecipitation, also referred as solvent displacement, is a one-step process suitable for producing nanoparticles loaded with hydrophobic drugs. The underlying physical principle is the interfacial deposition of a polymer, following the displacement of a water-compatible solvent from a lipophilic solution. Polymer and drug are dissolved in a semi-polar organic solvent (acetone, methanol, ethanol, acetonitrile); the resulting organic phase is mixed drop-wise in a water solution containing a stabilizer. This technique leads a narrow particle size distribution and allows avoiding the use of large amounts of toxic solvents as well as external energy sources. On the other hand, it is limited by drug solubility in the organic phase and it is thus not suitable for hydrophilic drugs; another drawback is the removal of the residual solvent.

Salting-out method is based on the addition of a polymer and drug solution in a water-compatible solvent (acetone, acetonitrile, tetrahydrofuran) to an aqueous solution that contains the salting-out agent (electrolytes like magnesium chloride and calcium chloride or non-electrolytes like sucrose) and a stabilizer, under stirring. This allows obtaining an $\mathrm{o} / \mathrm{w}$ emulsion that is subsequently diluted with large volumes of water, promoting the formation of particles by virtue of the diffusion of the water-compatible solvent toward the aqueous phase. Particles are recovered and purified by means of centrifugation or filtration. In particular, salt residues must be removed before utilization.

Salting-out is the ideal process for encapsulating heat-sensitive molecules (such as proteins, DNA, RNA) because no heating 
TABLE 4 | Examples of nanoparticles synthesis by means of emulsion-based methods.

\begin{tabular}{|c|c|c|c|}
\hline Loaded drug & Preparation method & Particle size [nm] & References \\
\hline Bovine Serum Albumin & Double emulsion & $140-250$ & Gao et al., 2005 \\
\hline Nimesulide & Emulsion-solvent evaporation & $160-2,150$ & Freitas and Marchetti, 2005 \\
\hline Tetanus toxoid & Double emulsion & $353-1,153$ & Bilati et al., 2005 \\
\hline Lysozyme & Double emulsion & $369-459$ & Bilati et al., 2005 \\
\hline Insulin & Double emulsion & $1,000-1,400$ & Bilati et al., 2005 \\
\hline Betamethasone phosphate & $\mathrm{O} / \mathrm{w}$ emulsion & $90-250$ & Ishihara et al., 2005 \\
\hline Vanillin & $\mathrm{O} /$ w emulsion & 240 & Dalmolin et al., 2016 \\
\hline Hemoglobin & Double emulsion & $122-185$ & Sheng et al., 2009 \\
\hline Neurotoxin-I & Double emulsion & 65 & Cheng et al., 2008 \\
\hline Triclosan & Double emulsion & $207-286$ & Pinon-Segundo et al., 2005 \\
\hline Paclitaxel & Single emulsion & 110 & Feng et al., 2015 \\
\hline
\end{tabular}

TABLE 5 | Examples of nanoparticles synthesis by means of precipitation-based methods.

\begin{tabular}{|c|c|c|c|}
\hline Loaded drug & $\begin{array}{l}\text { Preparation } \\
\text { method }\end{array}$ & $\begin{array}{l}\text { Particle size } \\
\text { [nm] }\end{array}$ & References \\
\hline Sodium cromoglycate & Nanoprecipitation & $470-1,300$ & Peltonen et al., 2004 \\
\hline Lysozyme & Nanoprecipitation & $137-351$ & Bilati et al., 2005 \\
\hline Tyrphostin & Nanoprecipitation & $65-143$ & Chorny et al., 2002 \\
\hline Cloricromene & Nanoprecipitation & $120-340$ & Leo et al., 2004 \\
\hline- & Nanoprecipitation & $100-300$ & Legrand et al., 2007 \\
\hline- & Salting out & $100-400$ & Zweers et al., 2003 \\
\hline- & Salting out & 279 & Nguyen et al., 2003 \\
\hline- & Salting out & 248 & Zweers et al., 2004 \\
\hline Savoxepine & Salting out & $274-736$ & Leroux et al., 1996 \\
\hline- & Dialysis & $40-250$ & Lo et al., 2005 \\
\hline Epirubicin & Dialysis & 128-1,088 & Liu et al., 2007 \\
\hline Paclitaxel & Dialysis & $367-475$ & Zhang et al., 2008 \\
\hline HIV p24 protein & Dialysis & 200 & Aline et al., 2009 \\
\hline
\end{tabular}

steps are required. Anyway, the process requires the optimization of parameters like salt type and concentration, type of polymer and solvent, and their relative amounts. The principal limitations are the intensive purification of the resulting nanoparticles as well as incompatibility issues concerning most of the employed salts with bioactive compounds.

Dialysis emerged as a simple process that allows obtaining small particles with a narrow size distribution. The polymer is dissolved in an organic solvent and placed in a dialysis tube of suitable pore size; dialysis is subsequently carried out in a solvent that is miscible with the organic phase but not compatible with the polymer. This leads to the formation of polymer particles due to the loss in solubility. Selected examples from literature of particles synthesized by means of precipitation based-methods are reported in Table 5.

\section{Compositing Methods}

In spray drying technique, polymer and drug are dissolved in an organic solvent and subsequently dispersed as ultra-fine droplets in a hot air flow. The solvent evaporates instantaneously and dried particles are collected under low pressure in dry air flow. Spray drying process is easy to perform and can be potentially employed at industrial scale. However, productivity can be hindered by the adhesion of the particles to the walls of the spray dryer and their agglomeration. Moreover, it is challenging to control drug distribution.

Melting technique allows avoiding the use of organic solvents but implies the dissolution of the drug in a polymer melt; therefore, it is not suitable for encapsulating active compound that are subjected to thermal degradation. Drug/polymer melt is subsequently solidified and cooled down with water or dry air. Particles are obtained through grounding or milling; in order to achieve small particles with narrower size distribution, the ground melt can be emulsified in a hot solution with a stabilizer. Despite the absence of organic solvents, this approach is limited by the thermal treatment of the drug/polymer system and the high number of steps needed to obtain smooth particles.

In situ-forming techniques aim at overcoming the most common drawbacks of the discussed processes, such as solvent removal, particles recovering, and resuspension. A drug/polymer solution (in a water-miscible solvent) is prepared and injected in the target site. When in contact with physiological fluids, polymer phase hardens and precipitates forming microparticles that entrap the active compound. The main drawback lies in a careful choice of the solvent, whose side-effects must be previously investigated.

\section{Other Approaches}

Supercritical fluids-based methods attracted a lot of interest because of their advantages, such as the use of environmentally friendly solvent and the possibility to obtain nanoparticles with (virtually) no traces of residual solvents. There are two main processes that involve supercritical fluids: rapid expansion of supercritical solution (RESS) and rapid expansion of a supercritical solution into a liquid solvent (RESOLV).

In RESS technique, the polymer is dissolved into the supercritical fluid; the solution is then subjected to a rapid expansion across a nozzle in ambient air. The sudden reduction in pressure leads to a substantial supersaturation, which, in 
turn, promotes homogeneous nucleation and the formation of well-dispersed particles. RESOLV process is based on the same principle, but the expansion does not take place in air but in a liquid solvent. The liquid phase hinders particle growth, leading to the synthesis of nanoparticles. The most important limitation of RESS and RESOLV technique is the poor solubility of the polymer in the supercritical fluid. In addition, it is difficult to control particle size and morphology.

With microfluidic techniques it is possible to obtain uniform particles with a narrow particle size distribution, which, in turn, allows a finer control of the release rate. The starting point is usually the attainment of an o/w emulsion in the microfluidic device, where monodisperse droplets can be achieved, followed by droplet solidification by means of solvent evaporation, diffusion or extraction. Particle size can be controlled by tuning the properties of oil and water phases (density, interfacial tension, and viscosity) and flow rates. Because of the inherent micron length scale, the challenge lies in the synthesis of particles at nanoscale. The underlying principle of hydrogel template method is the possibility to control sol-gel transition of physical gel by changing the environmental conditions (e.g., temperature). A warm aqueous gelling solution is distributed on a hard master template and placed at low temperature, in order to obtain a hydrogel mold. Polymer and drug are dissolved in a suitable solvent and poured on the hydrogel mold; solvent is removed through evaporation and particles are recovered by centrifugation or filtration and washed after dissolving the mold in water. Polyvinyl alcohol water-soluble molds are also employed. Similarly to microfluidic techniques, the drawback lies in the particle size, which is still limited to the micron length scale. In principle, nanoparticles can be obtained by means of nanostructured mold templates. Notably, nanoparticles can be produced not only from preformed polymers but also starting from monomers, including the polymerization process in the nanoparticle production step. This can be achieved my means of emulsion polymerization (George et al., 2019).

\section{Summary}

For the sake of completeness, the main advantages and disadvantages of the most common employed methods are summarized in Table 6.

As mentioned in the previous sections, several parameters are involved in process optimization and strongly influence the final particle size distribution. The most important degrees of freedom, as well as their influence on the final outcome are summarized in Table 7.

\section{THE NEW PARADIGM INTRODUCED BY NANOPARTICLES}

While devices at macroscale (suture treads, polymer-coated stents, bone fixation screws, etc.) remain at the implantation site, nanoparticles, because of their size, are able to spread all over the body and to penetrate into cells. This introduces a new paradigm in the engineering of polymeric nanocarriers, since they must be designed so that they remain in the systemic
TABLE 6 | Advantages and disadvantages of the most common nanoparticles production methods.

\begin{tabular}{|c|c|c|}
\hline Process & Advantages & Disadvantages \\
\hline $\begin{array}{l}\text { Single/double } \\
\text { emulsion }\end{array}$ & $\begin{array}{l}\text { Particle size can be } \\
\text { tuned acting on several } \\
\text { variables (Table } 7 \text { ) }\end{array}$ & $\begin{array}{l}\text { High shear rate } \\
\text { High volumes of water to } \\
\text { be removed }\end{array}$ \\
\hline Nanoprecipitation & $\begin{array}{l}\text { Nanoparticles have a } \\
\text { well-defined size and a } \\
\text { narrow size distribution } \\
\text { Less toxic solvents } \\
\text { No use of external } \\
\text { energy sources }\end{array}$ & $\begin{array}{l}\text { Extensive optimization of } \\
\text { polymer/solvent/non solvent } \\
\text { system } \\
\text { Not suitable only for } \\
\text { hydrophilic compounds }\end{array}$ \\
\hline Salting out & $\begin{array}{l}\text { No heating process } \\
\text { required } \\
\text { No } \\
\text { hazardous/chlorinated } \\
\text { solvents are employed }\end{array}$ & $\begin{array}{l}\text { Extensive optimization of } \\
\text { process conditions (type of salt } \\
\text { and its concentration, type of } \\
\text { polymer and solvent, and their } \\
\text { ratio) } \\
\text { Extensive purification to remove } \\
\text { salting-out agent } \\
\text { Possible incompatibility of salting } \\
\text { out agents and drugs }\end{array}$ \\
\hline $\begin{array}{l}\text { Supercritical } \\
\text { fluids-based } \\
\text { technology }\end{array}$ & $\begin{array}{l}\text { Environmentally friendly } \\
\text { solvents } \\
\text { Few traces of solvent in } \\
\text { the final product }\end{array}$ & $\begin{array}{l}\text { Limited by polymer solubility in } \\
\text { the supercritical fluid } \\
\text { Difficult to control particle size } \\
\text { and morphology; }\end{array}$ \\
\hline Spray drying & $\begin{array}{l}\text { Residual organic phase } \\
\text { is immediately } \\
\text { evaporated } \\
\text { Easy to set up }\end{array}$ & $\begin{array}{l}\text { It is difficult to control drug } \\
\text { distribution into the nanoparticles } \\
\text { Adhesion of nanoparticles to the } \\
\text { inner walls of spray dryer }\end{array}$ \\
\hline $\begin{array}{l}\text { Melting } \\
\text { techniques }\end{array}$ & No solvents required & $\begin{array}{l}\text { Not suitable for } \\
\text { thermally-sensitive compounds } \\
\text { (e.g., proteins) } \\
\text { Many steps are required }\end{array}$ \\
\hline $\begin{array}{l}\text { In situ forming } \\
\text { techniques }\end{array}$ & $\begin{array}{l}\text { No need to recover } \\
\text { particles }\end{array}$ & $\begin{array}{l}\text { Solvent toxicity must be } \\
\text { previously investigated. }\end{array}$ \\
\hline
\end{tabular}

TABLE 7 | Process variables and their effect on particle size.

\begin{tabular}{|c|c|}
\hline Process variable & Effect on average particle size \\
\hline Solvent & $\begin{array}{l}\text { It depends on the specific solvent, i.e., its effect } \\
\text { on emulsification. }\end{array}$ \\
\hline Surfactant/stabilizer & $\begin{array}{l}\text { It depends on the chemical nature of the } \\
\text { stabilizer (ionic/non-ionic). }\end{array}$ \\
\hline Shear rate & High shear rate decreases particle size. \\
\hline PLA molecular weight & $\begin{array}{l}\text { Size increases as molecular weight increases } \\
\text { (the viscosity of dispersed phase increases). }\end{array}$ \\
\hline PLA concentration & $\begin{array}{l}\text { Size increases as polymer concentration } \\
\text { increases (the viscosity of dispersed phase } \\
\text { increases). }\end{array}$ \\
\hline Stabilizer concentration & $\begin{array}{l}\text { High stabilizer concentration ( } 3 \% \text { w/v or higher) } \\
\text { decreases particle size. }\end{array}$ \\
\hline Viscosity of the dispersed phase & Size increases as viscosity increases. \\
\hline
\end{tabular}

circulation long enough to accomplish their task and they are able to target the desired objective. Particle behavior, in terms of clearance, biodistribution (i.e., distribution in the organs), cellular uptake, and toxicity are mainly influenced by particle size, shape, morphology, surface chemistry, and charge (Blanco 
TABLE 8 | Experimental techniques for nanoparticles characterization (Crucho and Barros, 2017).

\begin{tabular}{|c|c|}
\hline Experimental technique & Nanoparticle property \\
\hline Atomic Force Microscopy & $\begin{array}{l}\text { - Size and size distribution } \\
\text { - Shape } \\
\text { - Structure } \\
\text { - Aggregation } \\
\text { - Surface properties }\end{array}$ \\
\hline Differential scanning calorimetry & $\begin{array}{l}\text { - Physicochemical state and possible } \\
\text { interactions between drug } \\
\text { and polymer }\end{array}$ \\
\hline Dynamic light scattering & $\begin{array}{l}\text { - Particle size distribution } \\
\text { (hydrodynamic radius); }\end{array}$ \\
\hline Fluorescence microscopy & $\begin{array}{l}\text { - Critical association concentration } \\
\text { - Drug content } \\
\text { - In vitro drug release }\end{array}$ \\
\hline High performance liquid chromatography & $\begin{array}{l}\text { - Drug content } \\
\text { - In vitro drug release }\end{array}$ \\
\hline Infrared spectroscopy & $\begin{array}{l}\text { - Structure and conformation of } \\
\text { bioconjugates } \\
\text { - Functional group analysis }\end{array}$ \\
\hline Mass spectrometry & $\begin{array}{l}\text { - Molecular weight } \\
\text { - Composition } \\
\text { - Structure } \\
\text { - Surface properties }\end{array}$ \\
\hline Near-field scanning optical microscopy & $\begin{array}{l}\text { - Size } \\
\text { - Shape }\end{array}$ \\
\hline Nuclear magnetic resonance & $\begin{array}{l}\text { - Structure } \\
\text { - Composition } \\
\text { - Purity } \\
\text { - Conformational change }\end{array}$ \\
\hline Scanning electron microscopy & $\begin{array}{l}\text { - Size and particle size distribution } \\
\text { - Shape } \\
\text { - Aggregation }\end{array}$ \\
\hline Transmission electron microscopy & $\begin{array}{l}\text { - Size and particle size distribution } \\
\text { - Shape heterogeneity } \\
\text { - Aggregation }\end{array}$ \\
\hline X-ray photoelectron spectroscopy & $\begin{array}{l}\text { - Elemental and chemical composition } \\
\text { a the surface }\end{array}$ \\
\hline Zeta potential & - Stability referring to surface charge \\
\hline
\end{tabular}

et al., 2015). The techniques that can be used to characterize experimentally nanoparticles are summarized in Table 8 (Crucho and Barros, 2017).

The acquired knowledge led to the development of proper design strategies, as shown below (vide infra). Nanoparticles synthesized from PLA-based materials are mainly employed as devices for drug delivery for cancer treatment and for imaging purposes (Kim et al., 2019). Nanoparticles are potentially able to penetrate selectively within the cancer, where they can release the loaded active compound at the desired rate, so that a therapeutic effective drug concentration is maintained for a given time period. This allows minimizing the amount of administered drug, since it mainly diffuses in the tumor following nanoparticles permeation through cancer cells, dampening potential side effects and optimizing costs for health systems.

There are various administration routes for nanoparticles, such as oral, parenteral (intravenous, subcutaneous, intradermal, and intramuscular), respiratory, and transdermal routes (Kaialy and Al Shafiee, 2016). In any case, nanoparticles must be able to cross certain barriers (which can vary according to the administration route) in order to be effective (Blanco et al., 2015). Depending on the administration route, the first barrier can be constituted by endothelial or epithelial cells.

Epithelium is essentially constituted by the skin and mucosal membranes, while endothelium separates the blood flow from the surrounding tissues. The endothelium that separates blood vessel and central nervous system is the well-known blood brain barrier $(\mathrm{BBB})$, which is very challenging to cross.

Another barrier is constituted by the immune system; after injection, nanoparticles experience opsonization, which involves the adsorption of plasma proteins on the surface of the device that leads to the formation of the protein corona (vide infra). After the attainment of the layer of adsorbed proteins, nanoparticles bind to a macrophage receptor and are subsequently internalized and removed from circulation. This problem can be overcome through surface modification, hindering protein adsorption, and interactions with macrophages receptors. The most popular route is PEGylation, that is, the addition of PEG brushes on nanoparticle surface that constitute an obstacle for protein adsorption (Partikel et al., 2019). Other strategies involve surface functionalization with ad hoc peptides that delay phagocytic clearance (Rodriguez et al., 2013), or coating with cell membranes from red blood cells or leukocytes (Blanco et al., 2015). In general, the objective is to prolong the persistence in the blood circulation avoiding a rapid clearance by the immune system.

Focusing on PEGylation of PLA-based particles, three main approaches can be identified (Betancourt et al., 2009). In direct conjugation, PEG chains are covalently bound to the end groups of polymer chains already assembled in nanoparticles. This approach has the advantage that PEGylation is performed after the encapsulation of an active principle with standard techniques but it is not very efficient because of the limited exposure of the end groups on particle surface. When active conjugation in solution is chosen, preformed long polymer chains are activated and conjugated with PEG chains. Despite the moderate conjugation efficiency, the attainment of high yields is hindered by a difficult recover of the copolymer and the possible formation of PEG-PEG conjugates that can affect the purity of the product. The most used technique is ring opening polymerization, where preformed $\mathrm{OH}-\mathrm{PEG}-\mathrm{COOH}$ chains (that is, with a hydroxyl and a carboxyl end groups) are polymerized with lactide (and glycolide, if PLGA is needed) cyclic dimers. In these conditions, the hydroxyl end group of PEG acts as a protic agent initiating the reaction, while carboxyl end group remains intact. This leads to the synthesis of block PLA-PEG block copolymers.

Eventually, nanoparticles can experience cellular uptake mainly through endocytosis, which can be due to different pathways (Sahay et al., 2010; Kim et al., 2019). In receptormediated endocytosis, nanoparticles can be internalized by interacting with a specific receptor expressed on cellular membrane; a key role is played by clathrin and caveolin. Clathrinmediated endocytosis is present in essentially all mammalian cells and is responsible for the uptake of essential nutrients; caveolae-mediated endocytosis exploits the presence of caveolin 
proteins in the caveolae (lipid rafts along cellular membranes) and attracted some interest since this pathway allows bypassing lysosomes and thus avoiding lysosomal degradation. Carriermediated endocytosis exploits the presence of carrier proteins on cellular membrane; this pathway can be exploited to pass challenging barriers like the BBB. Since the cellular membrane, at physiological $\mathrm{pH}$, has a slight negative charge, electrostatic interactions with positively charged carriers can promote particle internalization through an adsorption-mediated endocytosis. Pinocytosis implies the formation of membrane-based vesicles from the cell surface, which captures solute and fluid from the environment.

From an experimental point of view, it is possible to identify the specific endocytosis pathway by suppressing some mechanisms with suitable inhibitors and assessing the cellular uptake.

In this regard, it useful to introduce the concept of targeting. In order to maximize their effect, nanoparticles should be able to selectively penetrate within the tumor, minimizing their accumulation in healthy organs. There are two different targeting approaches: passive and active targeting.

Passive targeting exploits the so called enhanced permeation and retention (EPR) effect; according to EPR, cancer exhibits an enhanced permeation due to the hyperpermeable vasculature and an enhanced retention because of the ineffective lymphatic drainage. Although EPR concept seems to be quite well-assessed in literature, its effectiveness is still debated since it is welldocumented for small animal models but human clinical data are less clear (Danhier, 2016).

Active targeting implies the functionalization of nanoparticle surface with suitable ligands (small molecules, proteins, carbohydrates, etc.), which can interact in a specific way with receptors that are overexpressed in diseased organs, tissues and cells (Bertrand et al., 2014). Since PLA has no reactive side groups, functionalization needs the synthesis of polymer chains with end groups that can be activated for further conjugation. In this regard, two strategies can be identified; pre-conjugation, where conjugated chains are obtained and subsequently assembled in nanoparticles with a suitable technique. This approach can be used for small ligands and peptides, while it is not suitable for proteins, since they can affect self-assembling process and conjugation needs organic solvents that can influence the secondary structure. Pre-conjugation allows introducing multiple ligands with one-step formulation procedure and a good control of particle properties. Post-conjugation involves the functionalization of preformed nanoparticles; this strategy is suitable for both small and big ligands (proteins, antibodies).

Notably, functionalization can be achieved also through the physical (that is, non-covalent) adsorption of targeting moieties on nanoparticle surface (Bertrand et al., 2014).

Summarizing, Dawidczyk et al. (2014) proposed general guidelines for the design of nanoparticles as carriers of active compounds, as shown in Table 9.

In the following paragraphs, some relevant examples from scientific literature are reported concerning PLA-based nanoparticles for drug delivery and imaging purposes. Given the extent of the topic, the following discussion does not claim
TABLE 9 | Design criteria for nanoparticles for drug delivery purposes (Dawidczyk et al., 2014).

\begin{tabular}{|c|c|c|}
\hline Function & Design requirements & Possible strategies \\
\hline Circulation & - Stable under flow at $37^{\circ} \mathrm{C}$ & $\begin{array}{l}\text { - Avoid binding with } \\
\text { components of blood } \\
\text { - Neutral or slightly } \\
\text { negative zeta potential }\end{array}$ \\
\hline Distribution & $\begin{array}{l}\text { - Minimize tissue } \\
\text { (peripheral) volume } \\
\text { - Minimize binding to } \\
\text { endothelium } \\
\text { - Minimize } \\
\text { paracellular transport }\end{array}$ & \\
\hline Elimination & $\begin{array}{l}\text { - Minimize opsonization } \\
\text { - Minimize recognition by } \\
\text { phagocytic cells } \\
\text { - Maximize circulation time } \\
\text { - Minimize rapid clearance } \\
\text { by the kidneys }\end{array}$ & $\begin{array}{l}\text { - Stealth coating } \\
\text { - diameter }>8 \mathrm{~mm} \text { to avoid } \\
\text { rapid clearance in kidneys }\end{array}$ \\
\hline Tumor accumulation & $\begin{array}{l}\text { - Maximize extravasation } \\
\text { across tumor vasculature }\end{array}$ & $\begin{array}{l}\text { - Diameter < } 200 \mathrm{~nm} \text { for } \\
\text { transport across leaky } \\
\text { vasculature through EPR } \\
\text { - Maintain high plasma } \\
\text { concentration } \\
\text { - Enhance EPR effect }\end{array}$ \\
\hline Tumor cell uptake & $\begin{array}{l}\text { - Maximize binding/uptake } \\
\text { by tumor cells } \\
\text { - Trafficking to } \\
\text { cellular compartment }\end{array}$ & $\begin{array}{l}\text { - Active or passive drug } \\
\text { release at tumor site } \\
\text { - Maximize cell } \\
\text { death/particle } \\
\text { - Maximize dose/particle } \\
\text { - Maximize endosomal } \\
\text { escape for particles taken } \\
\text { up by endocytosis }\end{array}$ \\
\hline
\end{tabular}

to be exhaustive, but aims at presenting some opportunities in the field.

\section{Nanoparticles for Drug Delivery}

Shalgunov et al. (2017) systematically investigated the effect of PEG coverage, injected dose and release kinetics on the performance of PLA-PEG nanoparticles loaded with vincristine (an anticancer active compound), determining their impact on pharmacokinetics and biodistribution in in vivo animal model.

Pavot et al. (2013) synthesized PLA nanoparticles containing Nod1 and Nod 2 receptors ligand; the aim is to induce a systemic immune response to improve the efficacy of vaccine delivery applications. Experimental outcomes showed promising results.

Zhou et al. (2018) developed nanoparticles based on hydroxyehyl starch-polylactide (HES-PLA) polymer, where they loaded two active compounds: doxorubicin and the TGF- $\beta$ inhibitor LY2157299. This strategy involving combined delivery aims at suppressing both tumor growth and metastasis.

Medel et al. (2017) developed PLA-PEG nanoparticles loaded with anticancer drugs curcumin and bortezomib. These active compounds are highly hydrophobic and show synergistic effects; in addition, they can form a covalent complex stable at physiological $\mathrm{pH}$ but labile at midly acidic $\mathrm{pH}$ (such as cancer microenvironment). The use of nanoparticles improved the 
cytotoxicity provided by curcumin-bortezomib if compared to free, not-encapsulated drugs.

Raudszus et al. (2018) synthesized PLA nanoparticles using a newly developed stabilizer, a vinyl sulphone-modified poly(vinyl alcohol) (VS-PVA) derivative. By virtue of its enhanced reactivity, VS-PVA derivative allowed an easy functionalization of particle surface with targeting moieties such as Ovalbumin, Apolipoprotein E (ApoE), and Penetratin. In particular, ApoE and Penetratin functionalized particles exhibited a higher cellular uptake, associated to a specific interactions with cellular receptors.

Zhu et al. (2016) developed nanoparticles made of D$\alpha$-tocopherol polyethylene glycol succinate-poly(lactide) (TPGS-PLA) loaded with docetaxel, an anticancer compound. Nanoparticles were coated with polydopamine and functionalized with glucosamine in order to enhance cellular uptake in the liver through ligand-mediated endocytosis.

Zhang et al. (2016) synthesized PLA-PEG nanoparticles loaded with paclitaxel and functionalized with EGFP-EGF1 covalently bound to PEG brushes. In vivo experiments showed that such particles are able to target multiple types of key cells in tumor tissues.

Turino et al. (2017) developed paclitaxed-loaded PLGA nanoparticles functionalized with ferritin. Functionalization was possible thanks to the use of PLGA-NHS polymer, where one end group is constituted by succinimidyl ester, which reacts with protein amine groups. Nanoparticles were also loaded with a guanidinium-based (Gd-DOTAMA) agent for magnetic resonance imaging (MRI). Experimental studies in vitro proved the targeting capability using breast cancer cell lines.

Gourdon et al. (2017) investigated PLA-PEG nanoparticles loaded with acyclovir (antiviral drug) and functionalized with single amino acids or short peptides in order to target PepT1 intestinal transporter. Functionalization was performed by covalently linking amino acids to PEG chains with an amine end group. Valine-functionalized nanoparticles showed the best outcomes in terms of targeting.

Cui and Zhu (2016) prepared doxorubicin-loaded PLA nanoparticles, covered with polyethylene imine (PEI) that was functionalized with Herceptin, a monoclonal antibody, which targets the human epidermal growth factor receptor 2 (HER2), overexpressed in breast cancer. Functionalization improved cellular uptake and nanoparticles proved to enhance the therapeutic effect of the drug reducing side effects.

Xiong et al. (2016) synthesized a block copolymer containing folic acid, pluronic (a polyethylene oxide-poly propylene oxide-polyethylene oxide block copolymer) and lactic acid. Resulting product was employed to produce paclitaxel-loaded nanoparticles. Experimental data proved that folate included in polymer chain could be used for active targeting with folate receptor expressed in ovarian cancer cells.

Coolen et al. (2019) synthesized PLA nanoparticles, which exhibit a negative charge on the surface due to lactic acid resulting from degradation. In order to non-covalently bind mRNA on the surface (they are both negatively charged), the authors firstly created a non-covalent complex between mRNA and cationic cell penetrating peptides (CPPs), which could be adsorbed on PLA surface.

Tang et al. (2018) obtained PLA-PEG micelles loaded with paclitaxel, an anticancer drug. They functionalized the surface with a CPP linked to PEG polymer with a $\mathrm{pH}$ sensitive sequence composed of histidine and glutamic acid. At physiological $\mathrm{pH}, \mathrm{CPP}$, and the linker are strongly bound through electrostatic interactions between glutamic acid (in the linker) and arginine (in the CPP). The mildly acidic $\mathrm{pH}$ of the tumor microenvironment leads to the protonation of some histidine residues of the linker, which interfere with the linker/CPP electrostatic interactions. The immediate consequence is an increased exposure of the CPP in the cancer and thus a more effective targeting, which could be achieved with stimuli responsive device ( $\mathrm{pH}$, in this case).

Song et al. (2016) developed PLA-PEG nanoparticles loaded with AZD2811, a hydrophobic anticancer active compound. The authors extensively tested the hydrophobic ion pairing (HIP) approach in order to maximize drug loading and encapsulation efficiency. They evaluated different hydrophobic counterions (such as oleic acid, cholic acid, and so on) that increase AZD2811 hydrophobicity through the formation of ion pairs. Different counterions led to different release kinetics, which allowed obtaining a library of particle formulations.

Medina et al. (2019) synthesized PLA-PEG and PLGA nanoparticles, blended with low molecular weight PLA and PCL and lipid-conjugate PEG, respectively. They observed that this blending improved the encapsulation efficiency of adapalene (a topical retinoid). Blending had a moderate impact on release kinetics.

Discussed examples are summarized in Table $\mathbf{1 0 .}$

\section{Nanoparticles for Imaging}

Banerjee et al. (2017) radiolabeled with ${ }^{111}$ In-containing moieties and IRDye680RD PLA-PEG nanoparticles functionalized with prostate-specific membrane antigen (PSMA) moieties. In vivo and ex vivo imaging allowed determining the distribution of both PSMA-functionalized and not-functionalized particles in the tumor. Xiong et al. (2017) treated $\mathrm{Fe}_{3} \mathrm{O}_{4}$ iron oxide nanoparticles with PLA-PEG chains for MRI purposes. End groups of PLA-PEG chains where functionalized with D-glucosamine as targeting agent. In vivo MRI in tumor-bearing mice confirmed the ability of the nanoparticles to target the cancer and their potential as contrast agents.

Dos Santos et al. (2017) synthesized PLA nanoparticles loaded with betamethasone and dexamethasone (antiflammatory drugs) and labeled with technetium-99m. Experiments showed that betamethasone loaded particles were able to accumulate in the inflammation site in an in vivo model of S. aureus infection.

Kerr et al. (2017) synthesized dye-PLLA-conjugates using Difluoroboron $\beta$-Diketonates as dyes, which were subsequently employed to obtain nanoparticles (average diameter $55 \mathrm{~nm}$ ) for imaging purposes. In order to improve stability, the authors added PDLA-PEG to promote stereocomplexation. In vivo experiments proved the ability of such particles to target tumors. 
TABLE 10 | Summary of discussed examples of nanoparticles for drug delivery.

\begin{tabular}{|c|c|c|c|c|c|c|}
\hline System & Preparation method & Average size [nm] & Loaded compounds & Main features & In vivo & References \\
\hline PLA-PEG & Single emulsion & 100 & Vincristine & $\begin{array}{l}\text { Systematic investigation of } \\
\text { PEG coverage, release } \\
\text { kinetics and injected dose }\end{array}$ & Yes & Shalgunov et al., 2017 \\
\hline PLA & Nanoprecipitation & 200 & Nod receptor ligands & $\begin{array}{l}\text { Induced systemic immune } \\
\text { response for vaccine } \\
\text { delivery }\end{array}$ & Yes & Pavot et al., 2013 \\
\hline PLA-PEG & Nanoprecipitation & $100-150$ & $\begin{array}{l}\text { Curcumin, curcumin and } \\
\text { bortezomib }\end{array}$ & $\begin{array}{l}\text { Synergistic effects with } \\
\text { co-delivery }\end{array}$ & No & Medel et al., 2017 \\
\hline PLA-VS-PVA & Double emulsion & 220 & Lumogen Red (dye) & $\begin{array}{l}\text { New stabilizer for easier } \\
\text { surface functionalization }\end{array}$ & No & Raudszus et al., 2018 \\
\hline TPGS-PLA & Single emulsion & 200 & Docetaxel & $\begin{array}{l}\text { Nanoparticles coated with } \\
\text { polydopamine and } \\
\text { functionalized with } \\
\text { galactosamine }\end{array}$ & Yes & Zhu et al., 2016 \\
\hline PLGA-PEG & Single emulsion & 150 & Paclitaxel & $\begin{array}{l}\text { Surface functionalization } \\
\text { with ferritin for targeting, } \\
\text { Gd-DOTAMA as imaging } \\
\text { agent }\end{array}$ & No & Turino et al., 2017 \\
\hline PLA-PEG & Nanoprecipitation & $30-50$ & Acyclovir & $\begin{array}{l}\text { Surface functionalization } \\
\text { with amino acids }\end{array}$ & Yes & Gourdon et al., 2017 \\
\hline PLA-PEI & Single emulsion & $140-220$ & Doxorubicin hydrochloride & $\begin{array}{l}\text { Surface functionalization } \\
\text { with antibodies }\end{array}$ & Yes & Cui and Zhu, 2016 \\
\hline FA-Pluronic-PLA & Dialysis & $190-260$ & Paclitaxel & $\begin{array}{l}\text { Synthesis of block } \\
\text { copolymer with folate } \\
\text { groups that target folate } \\
\text { receptors }\end{array}$ & Yes & Xiong et al., 2016 \\
\hline PLA-PEG PLGA & Single emulsion & $115-130$ & Adapalene & $\begin{array}{l}\text { Blending with short chains } \\
\text { of aliphatic polyesters or } \\
\text { lipid improves encapsulation }\end{array}$ & Yes & Medina et al., 2019 \\
\hline
\end{tabular}

\section{TOXICITY OF POLYLACTIC-BASED NANOPARTICLES}

Nanoparticles behavior mainly depends on size, shape, morphology, and surface charge; this holds also for their unwanted side effects. Entering into cells, nanoparticles can provide cytotoxic effects, leading to the disruption of cell membranes or cytosolic components or to programmed cell death (apoptosis). Typical adverse effects are oxidative stress [an excess of reactive oxygen species (ROS) or reactive nitrogen species (RNS) usually neutralized by cells], apoptosis, cytokine activation (due to inflammatory response), loss of mitochondrial, and lysosomal stability. They can also be a source of genotoxic effects, damaging DNA (Ganguly et al., 2018).
In addition, nanoparticles may induce haemolysis (disruption of red blood cells) or blood coagulation (causing thrombosis) (Dobrovolskaia and McNeil, 2007). PLA-based nanoparticles may provide additional side effects through their degradation products.

Toxicity assessment in vitro in usually performed by exposing cells to given dose of the potential toxic agent and measuring, e.g., cell viability and proliferation, mitochondrial activity, ROS production, cytokine activation through suitable assays.

In vivo experiments aim at assessing the pharmacokinetics of nanoparticles, their distribution in the organ and their clearance.

While in vitro and in vivo testing are usually performed when a new formulation is discussed (vide supra) up to author's best knowledge, there are few systematic 
studies concerning toxicity of PLA-based nanoparticles (Da Luz et al., 2017; Da Silva et al., 2019).

Singh and Ramarao (2013), e.g., observed that PLA nanoparticles in vitro did not provide detrimental effect concerning RNS, cytokine activation, mitochondrial or lysosomal integrity. At high concentration, they stimulated ROS production and inflammation; this was linked to the accumulation of polymer degradation products in the cell.

There is an additional intrinsic risk of toxic responses when nanoparticles are used and injected in the blood stream. Nanoparticles interact with the components present in the environment (proteins, carbohydrates, small molecules, etc.) through their surface. The driving force leading to the formation of this nano-bio interface are already known in scientific literature and are basically due to electrostatic and Van der Waals interactions as well as hydrophobic and depletion effects (Nel et al., 2009). One of the main outcomes from this network of interactions is the attainment of a layer of adsorbed proteins on nanoparticle surface, usually referred as protein corona (Cedervall et al., 2007). Because of the interactions with the surface, adsorbed proteins can be subjected to relevant structural changes, which can lead to aggregation and fibrillation, loss of enzymatic activity, or the exposure of new antigenic epitopes. Such side effects emerge from the specific protein-surface interactions: while, as mentioned, driving forces are known, they depend on many factors (materials, $\mathrm{pH}$, ionic strength, etc.) and are challenging to be determined a priori.

In vitro experiments allow a rapid and cost-effective evaluation of toxicity if compared to in vivo experiments with animal models (and the related ethical concerns). However, the possible lack of correlation between in vitro-in vivo tests, the challenging extrapolation of animal data to human patients and the shortage of harmonized protocols are still obstacles for extensive clinical trials (Dobrovolskaia and McNeil, 2013).

\section{REFERENCES}

Alexis, F. (2005). Factors affecting the degradation and drug-release mechanism of poly(lactic acid) and poly[(lactic acid)-co-(glycolic acid)]. Polym. Int. 54, 36-46. doi: $10.1002 /$ pi.1697

Aline, F., Brand, D., Pierre, J., Roingeard, P., Severine, M., Verrier, B., et al. (2009). Dendritic cells loaded with HIV-1 p24 proteins adsorbed on surfactant-free anionic PLA nanoparticles induce enhanced cellular immune responses against HIV-1 after vaccination. Vaccine 27, 5284-5291. doi: 10.1016/j.vaccine.2009.05.028

Armentano, I., Gigli, M., Morena, F., Argentati, C., Torre, L., and Martino, S. (2018). Recent advances in nanocomposites based on aliphatic polyesters: design, synthesis, and applications in regenerative medicine. Appl. Sci. 8:1452. doi: 10.3390/app8091452

Banerjee, S. R., Foss, C. A., Horhota, A., Pullambhatla, M., McDonnell, K., Zale, S., et al. (2017). In-111- and IRDye800CW-labeled PLA-PEG nanoparticle for imaging prostate-specific membrane antigen-expressing tissues. Biomacromolecules 18, 201-209. doi: 10.1021/acs.biomac. $6 \mathrm{~b} 01485$

Bertrand, N., Wu, J., Xu, X. Y., Kamaly, N., and Farokhzad, O. C. (2014). Cancer nanotechnology: the impact of passive and active targeting in the era of modern cancer biology. Adv. Drug Deliv. Rev. 66, 2-25. doi: 10.1016/j.addr.2013. 11.009

\section{CONCLUSIONS}

PLA—based polymers have been extensively studied in literature and are currently an established reality in the biomedical field, thanks to their interesting properties. This led to a growing interest also in the nanomedicine field for the synthesis of nanoparticles for drug delivery and imaging purposes. Nanoparticles showed a great potential as nanocarriers to deliver poorly soluble drugs, proteins, and genes targeting the tumor and releasing the active compound at the desired rate, enhancing in the therapeutic effect.

The new perspective introduced by nanoparticles also brings new sources of toxicity connected with cytotoxicity and haemolysis; also protein corona can provide undesired side effects that are not easily predictable $a$ priori.

Nowadays, an extensive clinical application of nanoparticles is still hindered by an exhaustive assessment of potential toxic effects, which does not allow nanoparticles unleashing their full potential.

\section{AUTHOR CONTRIBUTIONS}

TC performed literature research and wrote the first draft of the paper. All authors discussed and approved the contents of the manuscript and contributed to its final version by reading and editing.

\section{FUNDING}

This study is part of the GoNanoBioMat project and has received funding from the Horizon 2020 framework program of the European Union, ProSafe Joint Transnational Call 2016, from the CTI (1.1.2018 Innosuisse) under grant agreement number 19267.1 PFNM-NM and from FCT Foundation for Science and Technology under the project PROSAFE/0001/2016.

Betancourt, T., Byrne, J. D., Sunaryo, N., Crowder, S. W., Kadapakkam, M., Patel, S., et al. (2009). PEGylation strategies for active targeting of PLA/PLGA nanoparticles. J. Biomed. Mater. Res. A 91a, 263-276. doi: 10.1002/jbm.a.32247

Bilati, U., Allemann, E., and Doelker, E. (2005). Nanoprecipitation versus emulsion-based techniques for the encapsulation of proteins into biodegradable nanoparticles and process-related stability issues. AAPS PharmSciTech. 6, E594-E604. doi: 10.1208/pt060474

Blanco, E., Shen, H., and Ferrari, M. (2015). Principles of nanoparticle design for overcoming biological barriers to drug delivery. Nat. Biotechnol. 33, 941-951. doi: $10.1038 /$ nbt.3330

Carrasco, F., Pages, P., Gamez-Perez, J., Santana, O. O., and Maspoch, M. L. (2010). Processing of poly(lactic acid): characterization of chemical structure, thermal stability and mechanical properties. Polym. Degrad. Stab. 95, 116-125. doi: 10.1016/j.polymdegradstab.2009.11.045

Casalini, T. (2017). Bioresorbability of polymers: chemistry, mechanisms, and modeling. Bioresor. Polymers Biomed. Appl. 120, 65-83. doi: 10.1016/B978-0-08-100262-9.00003-3

Cedervall, T., Lynch, I., Lindman, S., Berggard, T., Thulin, E., Nilsson, H., et al. (2007). Understanding the nanoparticle-protein corona using methods to quantify exchange rates and affinities of proteins for nanoparticles. Proc. Natl. Acad. Sci. U.S.A. 104, 2050-2055. doi: 10.1073/pnas.0608582104

Cheng, Q. Y., Feng, J., Chen, J. M., Zhu, X., and Li, F. Z. (2008). Brain transport of neurotoxin-I with PLA nanoparticles through intranasal 
administration in rats: a microdialysis study. Biopharm. Drug Dispos. 29, 431-439. doi: 10.1002/bdd.621

Chorny, M., Fishbein, I., Danenberg, H. D., and Golomb, G. (2002). Lipophilic drug loaded nanospheres prepared by nanoprecipitation: effect of formulation variables on size, drug recovery and release kinetics. J. Controlled Release 83, 389-400. doi: 10.1016/S0168-3659(02)00211-0

Coolen, A. L., Lacroix, C., Mercier-Gouy, P., Delaune, E., Monge, C., Exposito, J. Y., et al. (2019). Poly(lactic acid) nanoparticles and cell-penetrating peptide potentiate mRNA-based vaccine expression in dendritic cells triggering their activation. Biomaterials 195, 23-37. doi: 10.1016/j.biomaterials.2018.12.019

Corneillie, S., and Smet, M. (2015). PLA architectures: the role of branching. Polym. Chem. 6, 850-867. doi: 10.1039/C4PY01572J

Crucho, C. I. C., and Barros, M. T. (2017). Polymeric nanoparticles: a study on the preparation variables and characterization methods. Mater. Sci. Eng. C Mater. Biol. Appl. 80, 771-784. doi: 10.1016/j.msec.2017.06.004

Cui, N., and Zhu, S. H. (2016). Monoclonal antibody-tagged polyethylenimine (PEI)/poly(lactide) (PLA) nanoparticles for the enhanced delivery of doxorubicin in HER-positive breast cancers. RSC Adv. 6, 79822-79829. doi: 10.1039/C6RA12616B

Da Luz, C. M., Boyles, M. S. P., Falagan-Lotsch, P., Pereira, M. R., Tutumi, H. R., Santos, E. D., et al. (2017). Poly-lactic acid nanoparticles (PLANP) promote physiological modifications in lung epithelial cells and are internalized by clathrin-coated pits and lipid rafts. J. Nanobiotechnol. 15:11. doi: 10.1186/s12951-016-0238-1

Da Silva, J., Jesus, S., Bernardi, N., Coleco, M., and Borges, O. (2019). Poly(D,LLactic Acid) nanoparticle size reduction increases its immunotoxicity. Front. Bioeng. Biotechnol. 7:137. doi: 10.3389/fbioe.2019.00137

Dalmolin, L. F., Khalil, N. M., and Mainardes, R. M. (2016). Delivery of vanillin by poly(lactic-acid) nanoparticles: development, characterization and in vitro evaluation of antioxidant activity. Mater. Sci. Eng. C Mater. Biol. Appl. 62, 1-8. doi: 10.1016/j.msec.2016.01.031

Danhier, F. (2016). To exploit the tumor microenvironment: since the EPR effect fails in the clinic, what is the future of nanomedicine? J. Controlled Release 244, 108-121. doi: 10.1016/j.jconrel.2016.11.015

Dawidczyk, C. M., Kim, C., Park, J. H., Russell, L. M., Lee, K. H., Pomper, M. G., et al. (2014). State-of-the-art in design rules for drug delivery platforms: lessons learned from FDA-approved nanomedicines. J. Controlled Release 187, 133-144. doi: 10.1016/j.jconrel.2014.05.036

Dobrovolskaia, M. A., and McNeil, S. E. (2007). Immunological properties of engineered nanomaterials. Nat. Nanotechnol. 2, 469-478. doi: 10.1038/nnano.2007.223

Dobrovolskaia, M. A., and McNeil, S. E. (2013). Understanding the correlation between in vitro and in vivo immunotoxicity tests for nanomedicines. J. Controlled Release 172, 456-466. doi: 10.1016/j.jconrel.2013.05.025

Dos Santos, S. N., Dos Reis, S. R. R., Pinto, S. R., Cerqueira-Coutinho, C., Nigro, F., Barja-Fidalgo, T. C., et al. and Santos-Oliveira, R. (2017). Antiinflammatory/infection PLA nanoparticles labeled with technetium 99m for in vivo imaging. J. Nanoparticle Res. 19:345. doi: 10.1007/s11051-017-4037-x

Fan, X. S., Wang, M. A., Yuan, D., and He, C. B. (2013). Amphiphilic conetworks and gels physically cross-linked via stereocomplexation of polylactide. Langmuir 29, 14307-14313. doi: 10.1021/la403432y

Farah, S., Anderson, D. G., and Langer, R. (2016). Physical and mechanical properties of PLA, and their functions in widespread applications - A comprehensive review. Adv. Drug Deliv. Rev. 107, 367-392. doi: 10.1016/j.addr.2016.06.012

Feng, X. Y., Gao, X. L., Kang, T., Jiang, D., Yao, J. H., Jing, Y. X., et al. (2015). Mammary-derived growth inhibitor targeting peptide-modified PEGPLA nanoparticles for enhanced targeted glioblastoma therapy. Bioconjug. Chem. 26, 1850-1861. doi: 10.1021/acs.bioconjchem.5b00379

Freitas, M. N., and Marchetti, J. M. (2005). Nimesulide PLA microspheres as a potential sustained release system for the treatment of inflammatory diseases. Int. J. Pharm. 295, 201-211. doi: 10.1016/j.ijpharm.2005.03.003

Ganguly, P., Breen, A., and Pillai, S. C. (2018). Toxicity of nanomaterials: exposure, pathways, assessment, and recent advances. ACS Biomater. Sci. Eng. 4, 2237-2275. doi: 10.1021/acsbiomaterials.8b00068

Gao, H., Wang, Y. N., Fan, Y. G., and Ma, J. B. (2005). Synthesis of a biodegradable tadpole-shaped polymer via the coupling reaction of polylactide onto mono(6(2-aminoethyl)amino-6-deoxy)-beta-cyclodextrin and its properties as the new carrier of protein delivery system. J. Controlled Release 107, 158-173. doi: 10.1016/j.jconrel.2005.06.010

Garlotta, D. (2001). A literature review of poly(lactic acid). J. Polym. Environ. 9, 63-84. doi: 10.1023/A:1020200822435

George, A., Shah, P. A., and Shrivastav, P. S. (2019). Natural biodegradable polymers based nano-formulations for drug delivery: a review. Int. J. Pharm. 561, 244-264. doi: 10.1016/j.ijpharm.2019.03.011

Gourdon, B., Chemin, C., Moreau, A., Arnauld, T., Baumy, P., Cisternino, S., et al. (2017). Functionalized PLA-PEG nanoparticles targeting intestinal transporter PepT1 for oral delivery of acyclovir. Int. J. Pharm. 529, 357-370. doi: 10.1016/j.ijpharm.2017.07.024

Hamad, K., Kaseem, M., Ayyoob, M., Joo, J., and Deri, F. (2018). Polylactic acid blends: the future of green, light and tough. Prog. Polym. Sci. 85, 83-127. doi: 10.1016/j.progpolymsci.2018.07.001

Ishihara, T., Izumo, N., Higaki, M., Shimada, E., Hagi, T., Mine, L., et al. (2005). Role of zinc in formulation of PLGA/PLA nanoparticles encapsulating betamethasone phosphate and its release profile. J. Controlled Release 105, 68-76. doi: 10.1016/j.jconrel.2005.02.026

Jing, Y. H., Quan, C. Y., Liu, B., Jiang, Q., and Zhang, C. (2016). A mini review on the functional biomaterials based on poly (lactic acid) stereocomplex. Polymer Rev. 56, 262-286. doi: 10.1080/15583724.2015.1111380

Kaialy, W., and Al Shafiee, M. (2016). Recent advances in the engineering of nanosized active pharmaceutical ingredients: promises and challenges. $A d v$. Colloid Interface Sci. 228, 71-91. doi: 10.1016/j.cis.2015.11.010

Kerr, C., Derosa, C. A., Daly, M. L., Zhang, H. T., Palmer, G. M., and Fraser, C. L. (2017). Luminescent difluoroboron beta-diketonate PLA-PEG nanoparticle. Biomacromolecules 18, 551-561. doi: 10.1021/acs.biomac.6b01708

Kim, K. T., Lee, J. Y., Kim, D. D., Yoon, I. S., and Cho, H. J. (2019). Recent progress in the development of poly(lactic-co-glycolic acid)-based nanostructures for cancer imaging and therapy. Pharmaceutics 11:E280. doi: 10.3390/pharmaceutics11060280

Lee, B. K., Yun, Y., and Park, K. (2016). PLA micro- and nano-particles. Adv. Drug Deliv. Rev. 107, 176-191. doi: 10.1016/j.addr.2016.05.020

Legrand, P., Lesieur, S., Bochot, A., Gref, R., Raatjes, W., Barratt, G., et al. (2007). Influence of polymer behaviour in organic solution on the production of polylactide nanoparticles by nanoprecipitation. Int. J. Pharm. 344, 33-43. doi: 10.1016/j.ijpharm.2007.05.054

Leo, E., Brina, B., Forni, F., and Vandelli, M. A. (2004). In vitro evaluation of PLA nanoparticles containing a lipophilic rug in water-soluble or insoluble form. Int. J. Pharm. 278, 133-141. doi: 10.1016/j.ijpharm.2004.03.002

Leroux, J. C., Allemann, E., Dejaeghere, F., Doelker, E., and Gurny, R. (1996). Biodegradable nanoparticles - from sustained release formulations to improved site specific drug delivery. J. Controlled Release 39, 339-350. doi: 10.1016/0168-3659(95)00164-6

Liu, M., Zhou, Z. M., Wang, X. F., Xu, J., Yang, K., Cui, Q., et al. (2007). Formation of poly(L,D-lactide) spheres with controlled size by direct dialysis. Polymer 48, 5767-5779. doi: 10.1016/j.polymer.2007.07.053

Lo, C. L., Lin, K. M., and Hsiue, G. H. (2005). Preparation and characterization of intelligent core-shell nanoparticles based on poly(D,L-lactide)-g-poly(Nisopropyl-acrylamide-co-methacrylic acid). J. Controlled Release 104, 477-488. doi: 10.1016/j.jconrel.2005.03.004

Medel, S., Syrova, Z., Kovacik, L., Hrdy, J., Hornacek, M., Jager, E., et al. (2017). Curcumin-bortezomib loaded polymeric nanoparticles for synergistic cancer therapy. Eur. Polym. J. 93, 116-131. doi: 10.1016/j.eurpolymj.2017.05.036

Medina, D. X., Chung, E. P., Bowser, R., and Sirianni, R. W. (2019). Lipid and polymer blended polyester nanoparticles loaded with adapalene for activation of retinoid signaling in the CNS following intravenous administration. J. Drug Deliv. Sci. Technol. 52, 927-933. doi: 10.1016/j.jddst.2019.04.013

Michalski, A., Brzezinski, M., Lapienis, G., and Biela, T. (2019). Star-shaped and branched polylactides: synthesis, characterization, and properties. Prog. Polym. Sci. 89, 159-212. doi: 10.1016/j.progpolymsci.2018.10.004

Murariu, M., and Dubois, P. (2016). PLA composites: from production to properties. Adv. Drug Deliv. Rev. 107, 17-46. doi: 10.1016/j.addr.2016. 04.003

Nagahama, K., Mori, Y., Ohya, Y., and Ouchi, T. (2007). Biodegradable nanogel formation of polylactide-grafted dextran copolymer in dilute aqueous solution and enhancement of its stability by stereocomplexation. Biomacromolecules 8 , 2135-2141. doi: 10.1021/bm070206t 
Nel, A. E., Madler, L., Velegol, D., Xia, T., Hoek, E. M. V., Somasundaran, P., et al. (2009). Understanding biophysicochemical interactions at the nano-bio interface. Nat. Mater. 8, 543-557. doi: 10.1038/nmat2442

Nguyen, C. A., Allemann, E., Schwach, G., Doelker, E., and Gurny, R. (2003). Synthesis of a novel fluorescent poly(D,L-lactide) end-capped with 1pyrenebutanol used for the preparation of nanoparticles. Eur. J. Pharm. Sci. 20, 217-222. doi: 10.1016/S0928-0987(03)00196-9

Partikel, K., Korte, R., Stein, N. C., Mulac, D., Herrmann, F. C., Humpf, H. U., et al. (2019). Effect of nanoparticle size and PEGylation on the protein corona of PLGA nanoparticles. Eur. J. Pharm. Biopharm. 141, 70-80. doi: 10.1016/j.ejpb.2019. 05.006

Pavot, V., Rochereau, N., Primard, C., Genin, C., Perouzel, E., Lioux, T., et al. (2013). Encapsulation of Nod1 and Nod2 receptor ligands into poly(lactic acid) nanoparticles potentiates their immune properties. J. Controlled Release 167, 60-67. doi: 10.1016/j.jconrel.2013.01.015

Peltonen, L., Aitta, J., Hyvonen, S., Karjalainen, M., and Hirvonen, J. (2004). Improved entrapment efficiency of hydrophilic drug substance during nanoprecipitation of poly(l)lactide nanoparticles. AAPS Pharmscitech. 5:E16. doi: 10.1007/BF02830584

Pinon-Segundo, E., Ganem-Quintanar, A., Alonso-Perez, V., and QuintanarGuerrero, D. (2005). Preparation and characterization of triclosan nanoparticles for periodontal treatment. Int. J. Pharm. 294, 217-232. doi: 10.1016/j.ijpharm.2004.11.010

Raudszus, B., Mulac, D., and Langer, K. (2018). A new preparation strategy for surface modified PLA nanoparticles to enhance uptake by endothelial cells. Int. J. Pharm. 536, 211-221. doi: 10.1016/j.ijpharm.2017.11.047

Rodenas-Rochina, J., Vidaurre, A., Cortazar, I. C., and Lebourg, M. (2015). Effects of hydroxyapatite filler on long-term hydrolytic degradation of PLLA/PCL porous scaffolds. Polym. Degrad. Stab. 119, 121-131. doi: 10.1016/j.polymdegradstab.2015.04.015

Rodriguez, P. L., Harada, T., Christian, D. A., Pantano, D. A., Tsai, R. K., and Discher, D. E. (2013). Minimal "Self" peptides that inhibit phagocytic clearance and enhance delivery of nanoparticles. Science 339, 971-975. doi: $10.1126 /$ science. 1229568

Sahay, G., Alakhova, D. Y., and Kabanov, A. V. (2010). Endocytosis of nanomedicines. J. Controlled Release 145, 182-195. doi: 10.1016/j.jconrel.2010.01.036

Saini, P., Arora, M., and Kumar, M. N. V. R. (2016). Poly(lactic acid) blends in biomedical applications. Adv. Drug Deliv. Rev. 107, 47-59. doi: 10.1016/j.addr.2016.06.014

Shalgunov, V., Zaytseva-Zotova, D., Zintchenko, A., Levada, T., Shilov, Y., Andreyev, D., et al. (2017). Comprehensive study of the drug delivery properties of poly(L-lactide)-poly (ethylene glycol) nanoparticles in rats and tumor-bearing mice. J. Controlled Release 261, 31-42. doi: 10.1016/j.jconrel.2017.06.006

Sheikh, Z., Najeeb, S., Khurshid, Z., Verma, V., Rashid, H., and Glogauer, M. (2015). Biodegradable materials for bone repair and tissue engineering applications. Materials 8, 5744-5794. doi: 10.3390/ma8095273

Sheng, Y., Yuan, Y., Liu, C. S., Tao, X. Y., Shan, X. Q., and Xu, F. (2009). In vitro macrophage uptake and in vivo biodistribution of PLA-PEG nanoparticles loaded with hemoglobin as blood substitutes: effect of PEG content. J. Mater. Sci. Mater. Med. 20, 1881-1891. doi: 10.1007/s10856-009-3746-9

Singh, R. P., and Ramarao, P. (2013). Accumulated polymer degradation products as effector molecules in cytotoxicity of polymeric nanoparticles. Toxicol. Sci. 136, 131-143. doi: 10.1093/toxsci/ kft179

Song, Y. H., Shin, E., Wang, H., Nolan, J., Low, S., Parsons, D., et al. (2016). A novel in situ hydrophobic ion paring (HIP) formulation strategy for clinical product selection of a nanoparticle drug delivery system. J. Controlled Release 229, 106-119. doi: 10.1016/j.jconrel.2016.03.026

Storti, G., and Lattuada, M. (2017). Synthesis of bioresorbable polymers for medical applications. Bioresor. Polymers Biomed. Appl. 120, 153-179. doi: 10.1016/B978-0-08-100262-9.00008-2
Sveinbjornsson, B. R., Miyake, G. M., El-Batta, A., and Grubbs, R. H. (2014). Stereocomplex formation of densely grafted brush polymers. ACS Macro Lett. 3, 26-29. doi: $10.1021 / \mathrm{mz} 400568 \mathrm{j}$

Tang, B. Q., Zaro, J. L., Shen, Y., Chen, Q., Yu, Y. L., Sun, P. P., et al. (2018). Acid-sensitive hybrid polymeric micelles containing a reversibly activatable cell-penetrating peptide for tumor-specific cytoplasm targeting. J. Controlled Release 279, 147-156. doi: 10.1016/j.jconrel.2018.04.016

Tsuji, H. (2016). Poly(lactic acid) stereocomplexes: a decade of progress. Adv. Drug Deliv. Rev. 107, 97-135. doi: 10.1016/j.addr.2016.04.017

Turino, L. N., Ruggiero, M. R., Stefania, R., Cutrin, J. C., Aime, S., and Crich, S. G. (2017). Ferritin decorated PLGA/paclitaxel loaded nanoparticles endowed with an enhanced toxicity toward MCF-7 breast tumor cells. Bioconjug. Chem. 28, 1283-1290. doi: 10.1021/acs.bioconjchem.7b00096

Tyler, B., Gullotti, D., Mangraviti, A., Utsuki, T., and Brem, H. (2016). Polylactic acid (PLA) controlled delivery carriers for biomedical applications. Adv. Drug Deliv. Rev. 107, 163-175. doi: 10.1016/j.addr.2016.06.018

Van De Velde, K., and Kiekens, P. (2002). Biopolymers: overview of several properties and consequences on their applications. Polym. Test. 21, 433-442. doi: 10.1016/S0142-9418(01)00107-6

Von Burkersroda, F., Schedl, L., and Gopferich, A. (2002). Why degradable polymers undergo surface erosion or bulk erosion. Biomaterials 23, 4221-4231. doi: 10.1016/S0142-9612(02)00170-9

Xiong, F., Hu, K., Yu, H. L., Zhou, L. J., Song, L. N., Zhang, Y., et al. (2017). A functional iron oxide nanoparticles modified with PLA-PEGDG as tumor-targeted MRI contrast agent. Pharm. Res. 34, 1683-1692. doi: 10.1007/s11095-017-2165-8

Xiong, X. Y., Tao, L., Qin, X., Li, Z. L., Gong, Y. C., Li, Y. P., et al. (2016). Novel folated Pluronic/poly(lactic acid) nanoparticles for targeted delivery of paclitaxel. RSC Adv. 6, 52729-52738. doi: 10.1039/C6RA09271C

Zhang, B., Jiang, T., Ling, L., Cao, Z. L., Zhao, J. J., Tuo, Y. Y., et al. (2016). Enhanced antitumor activity of EGFP-EGF1-conjugated nanoparticles by a multitargeting strategy. ACS Appl. Mater. Interfaces 8, 8918-8927. doi: 10.1021/acsami.6b00036

Zhang, Z. P., Lee, S. H., Gan, C. W., and Feng, S. S. (2008). In vitro and in vivo investigation on PLA-TPGS nanoparticles for controlled and sustained small molecule chemotherapy. Pharm. Res. 25, 1925-1935. doi: 10.1007/s11095-008-9611-6

Zhou, Q., Li, Y. H., Zhu, Y. H., Yu, C., Jia, H. B., Bao, B. H., et al. (2018). Co-delivery nanoparticle to overcome metastasis promoted by insufficient chemotherapy. J. Controlled Release 275, 67-77. doi: 10.1016/j.jconrel.2018.02.026

Zhu, D. W., Tao, W., Zhang, H. L., Liu, G., Wang, T., Zhang, L. H., et al. (2016). Docetaxel (DTX)-loaded polydopamine-modified TPGS-PLA nanoparticles as a targeted drug delivery system for the treatment of liver cancer. Acta Biomater. 30, 144-154. doi: 10.1016/j.actbio.2015.11.031

Zweers, M. L. T., Engbers, G. H. M., Grijpma, D. W., and Feijen, J. (2004). In vitro degradation of nanoparticles prepared from polymers based on DLlactide, glycolide and poly(ethylene oxide). J. Controlled Release 100, 347-356. doi: 10.1016/j.jconrel.2004.09.008

Zweers, M. L. T., Grijpma, D. W., Engbers, G. H. M., and Feijen, J. (2003). The preparation of monodisperse biodegradable polyester nanoparticles with a controlled size. J. Biomed. Mater. Res. B Appl. Biomater. 66b, 559-566. doi: $10.1002 / \mathrm{jbm} . \mathrm{b} .10046$

Conflict of Interest: The authors declare that the research was conducted in the absence of any commercial or financial relationships that could be construed as a potential conflict of interest.

Copyright (๑) 2019 Casalini, Rossi, Castrovinci and Perale. This is an open-access article distributed under the terms of the Creative Commons Attribution License (CC $B Y)$. The use, distribution or reproduction in other forums is permitted, provided the original author(s) and the copyright owner(s) are credited and that the original publication in this journal is cited, in accordance with accepted academic practice. No use, distribution or reproduction is permitted which does not comply with these terms. 